this study, as a part of the Women's Interagency HIV Study (WIHS) at Rush-Presbyterian St. Luke's Medical Center. Human investigation guidelines set forth by the US Department of Health and Human Services and Rush-Presbyterian St. Luke's Medical Center were observed. [Internal Review Board (IRB) approval No. 99031602]. Financial support provided by the WIHS Grant No. 5U01 AI34993-3 and National Institutes of Health Grant No. AI-31812 and Grant No. 2-P50-AR39239 from NIHNIAMS. Address correspondence to Dr. Farhad B. Hashemi, Department of Immunology/Microbiology, Rush University, 1653 W. Congress Pkwy. Chicago, IL 60612 USA.Internet:fhashem2@rush.edu

Received 16 June 1999; accepted 6 October 1999.

Farhad B. Hashemi, Gregory T. Spear, Lawrence Madsen and Juergen Mollenhauer Rush University Chicago, IL, USA

\section{Preparation of Sensitive and Specific Oligonucleotide Probes Tailed Using Terminal Transferase and dITP}

BioTechniques 28:486-490 (March 2000)

\section{ABSTRACT}

An oligonucleotide probe tailed with deoxyadenosine-5'-triphosphate or deoxythymine-5'-triphosphate is detectable with high sensitivity, but has a major drawback-the tail co-hybridizes specifically to complementary sequences. This can be a probem when screening $c D N A$ clones that contain poly(dA) sequences. While it is possible to mask the cDNA tail with unlabeled poly $(d A)$ or poly $(A)$ oligonucleotides, falsepositive clones are still produced because complete masking of extremely long $(d A)$ tails is difficult. As a result, only cDNA clones that have extremely long poly(dA) sequences are often obtained by hybridization screening using tailed probes. In this report, we describe an oligonucleotide probe tailed with DIG-labeled nucleotide in combination with deoxyinosine-5' -triphosphate that was highly specific and sensitive to cDNAs. Terminal deoxynucleotidyl transferase efficiently adds dI nucleotides to the 3 '-end. The dI of the tails did not pair with any nucleotides under stringent hybridization so that the specificity of hybridization assays remained high without affecting the sensitivity of the test. Colony hybridization experiments demonstrated that there were very few ( 1 of 80 tested) false positives using this technique. Its use may increase the accuracy of cDNA screening.

\section{INTRODUCTION}

Labeling of oligonucleotides is important for screening gene libraries using hybridization methods (10). A variety of nonisotopic labeling reactions are used for introducing a labeling molecule to a $3^{\prime}$ - or $5^{\prime}$-end $(3,4,7)$, some internal nucleotides (12) or the $3^{\prime}$-tail (5). Specificity to the oligonucleotide sequence is high when using end labeling; however, the sensitivity is low with nonisotopic labeling. The highest sensitivity is obtained by tailing, using DIG-labeled nucleotide in combination with deoxyadenosine- 5 '-triphosphate (dATP) as substrates of terminal deoxynucleotidyl transferase (TdT); however, the specificity is often reduced due to the added tail. This is especially true in screening cDNA clones: the homopolymeric dA tail hybridizes to $\mathrm{dA} / \mathrm{dT}$ regions in the cDNA clones derived from poly(A) sequences of eukaryotic mRNA (2) even if the regions in the cDNA are masked by the addition of unlabeled poly(dA) oligonucleotides. Thus, there has been no nonisotopic method of labeling an oligonucleotide probe for sensitive and specific cDNA screening using hybridization. In this study, we used deoxyinosine- $5^{\prime}$-triphosphate (dITP) in combination with DIG-deoxyuridine5 -triphosphate (DIG-dUTP) as the substrate for TdT tailing. The efficiency of labeling and the specificity of hybridization of the probe were evaluated in comparison with probes tailed with dATP in combination with DIG-dUT

\section{MATERIALS AND METHODS}

\section{Materials}

dITP was purchased from Sigma (St. Louis, MO, USA). Positively charged nylon membranes were purchased from Roche Molecular Biochemicals (Mannheim, Germany). A synthetic oligonucleotide (5'-CCCTACAAAGAAAATGGAGAGCCT-3') to detect the testis-enhanced gene transcript (TEGT) gene was designed using an HYBsimulator ${ }^{\mathrm{TM}}$ (Advanced Gene Computing Technologies, Irvine, CA, USA). For the colony hybridization experiment, 275 types of synthetic oligonucleotides were designed. Synthetic oligonucleotides were purchased from Life Technologies (Gaithersburg, MD, USA). Plasmid DNA containing cDNA clones was obtained from a cDNA library (11).

\section{Tailing of Oligonucleotide Using TdT}

Oligonucleotide probes were tailed with DIG-labeled nucleotide using TdT 
from calf thymus (both from Roche Molecular Biochemicals). Each oligonucleotide (100 pmol) was incubated in TdT reaction buffer $(0.2 \mathrm{M}$ potassium cacodylate, $25 \mathrm{mM}$ Tris- $\mathrm{HCl}, \mathrm{pH}$ 6.6, $0.25 \mathrm{mg} / \mathrm{mL}$ bovine serum albumin, 5 $\mathrm{mM} \mathrm{CoCl} 2$ ) with $0.05 \mathrm{mM}$ DIG-dUTP and $2.5 \mathrm{U} / \mu \mathrm{L}$ TdT in the presence of 0.1 or $0.5 \mathrm{mM}$ dITP or dATP for 15 $\min$ at $37^{\circ} \mathrm{C}$. The reaction was stopped with the addition of $10 \mu \mathrm{g} / \mathrm{mL}$ glycogen and $0.2 \mathrm{mM}$ EDTA. The tailed probe was precipitated by ethanol and dissolved in $100 \mu \mathrm{L}$ water. It was applied to $15 \%$ (wt/vol) polyacrylamide gels with the buffer containing $25 \mathrm{mM}$ Tris and $192 \mathrm{mM}$ glycine ( $\mathrm{pH}$ 7.9) to determine the tail length. Gels were silver stained using a kit from Daiichi Pure Chemicals (Tokyo, Japan).

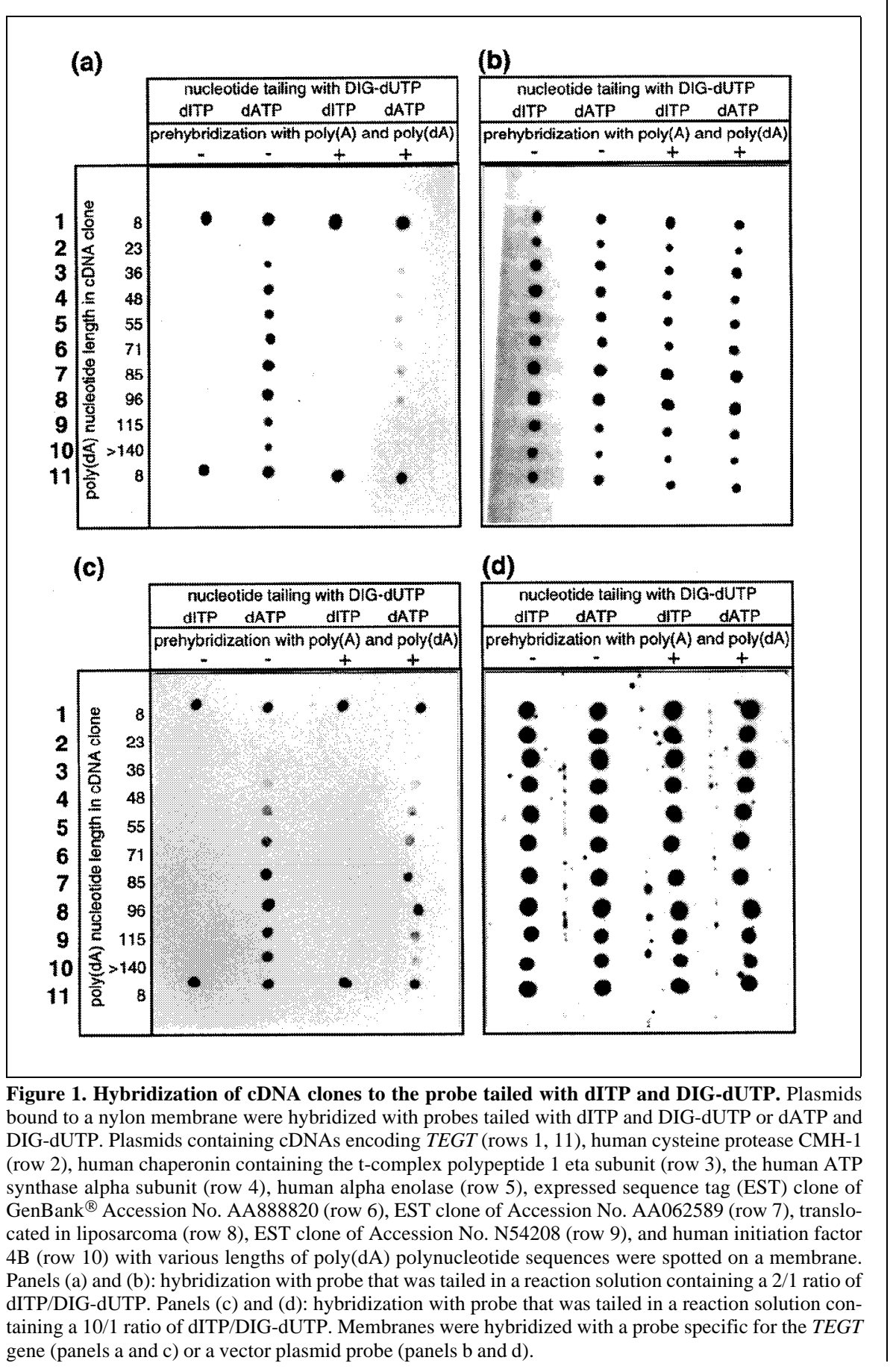




\section{Short Technical Reports}

Table 1. Colony Hybridization Specificity of Oligodeoxynucleotides Tailed with dITP and DIG-dUTP

\begin{tabular}{|c|c|c|c|c|c|c|}
\hline & \multirow{2}{*}{$\begin{array}{l}\text { Total Clone } \\
\text { Number }\end{array}$} & \multirow{2}{*}{$\begin{array}{l}\text { Sequencing } \\
\text { Success Rate }\end{array}$} & \multicolumn{2}{|c|}{$\begin{array}{l}\text { Idenity of Sequenced Clone } \\
\text { to the Target Gene of Probe } \\
\text { by BLASTn }\end{array}$} & \multicolumn{2}{|c|}{$\begin{array}{l}\text { Probe Sequence Within the } \\
\text { Identical Clone }\end{array}$} \\
\hline & & & Identical & Not Identical & Including & Not Including \\
\hline Positive clones & 10 & $9 / 10$ & 8 & 1 & 8 & 0 \\
\hline Negative clones & 70 & $58 / 70$ & 3 & 55 & 0 & 3 \\
\hline
\end{tabular}

\section{Hybridization}

Plasmids were denatured for $5 \mathrm{~min}$ at $96^{\circ} \mathrm{C}$, spotted onto nylon membranes and cross-linked using a Stratalinker ${ }^{\circledR}$ UV cross-linker (Stragene, La Jolla, CA, USA). Membranes were prehybridized in hybridization solution [6x standard saline citrate (SSC), 1\% (wt/ vol) blocking reagent (Roche Molecular Biochemicals), $0.1 \%$ (wt/vol) $N$-lauroylsarkosine, $0.02 \%(\mathrm{wt} / \mathrm{vol}) \mathrm{SDS}$ ] with or without $0.1 \mathrm{mg} / \mathrm{mL}$ poly(A) and $5 \mathrm{mg} / \mathrm{mL}$ poly $(\mathrm{dA})$ solution for $3 \mathrm{~h}$ at $68^{\circ} \mathrm{C}$, followed by hybridization with 5 $\mathrm{pmol} / \mathrm{mL}$ tailed probe in hybridization solution for $12 \mathrm{~h}$ at $60^{\circ} \mathrm{C}$. The membranes were washed $4 \times$ with $6 \times \mathrm{SSC}$, $0.1 \%$ (wt/vol) SDS for $15 \mathrm{~min}$ at $60^{\circ} \mathrm{C}$. Hybridized probes were detected using a DIG luminescence detection system.

\section{Preparation of High-Density Colony Filters}

High-density filters (HDF) were prepared using a Biomek $2000^{\circledR}$ robotics workstation with a 384-pin tool (Beckman Coulter, Fullerton, CA, USA). Transformants cultured in nine 384-well plates were spotted onto a nylon membrane filter $(11 \times 7.5 \mathrm{~cm})$ on LB medium in a $3 \times 3$ array and incubated at $37^{\circ} \mathrm{C}$ for $24 \mathrm{~h}$. HDF were then treated as described (8) for subsequent hybridization with probes tailed with dITP and DIG-dUTP.

\section{Sequencing}

Plasmids appearing in the first row, first column of each array were prepared from the original transformants stock. The $5^{\prime}$ sequences of these clones were determined using BigDye $^{\mathrm{TM}}$ Terminator Cycle Sequencing (PE Biosystems, Foster City, CA, USA). The sequences were compared with nucleotide sequences in the GenBank $^{\circledR}$ database using WU-BLAST $2.0^{\odot}$ (1) to identify the cDNA clones.

\section{RESULTS AND DISCUSSION}

\section{Tailing with dITP and DIG-dUTP Using TdT}

The oligonucleotide for the TEGT gene was labeled to evaluate the length

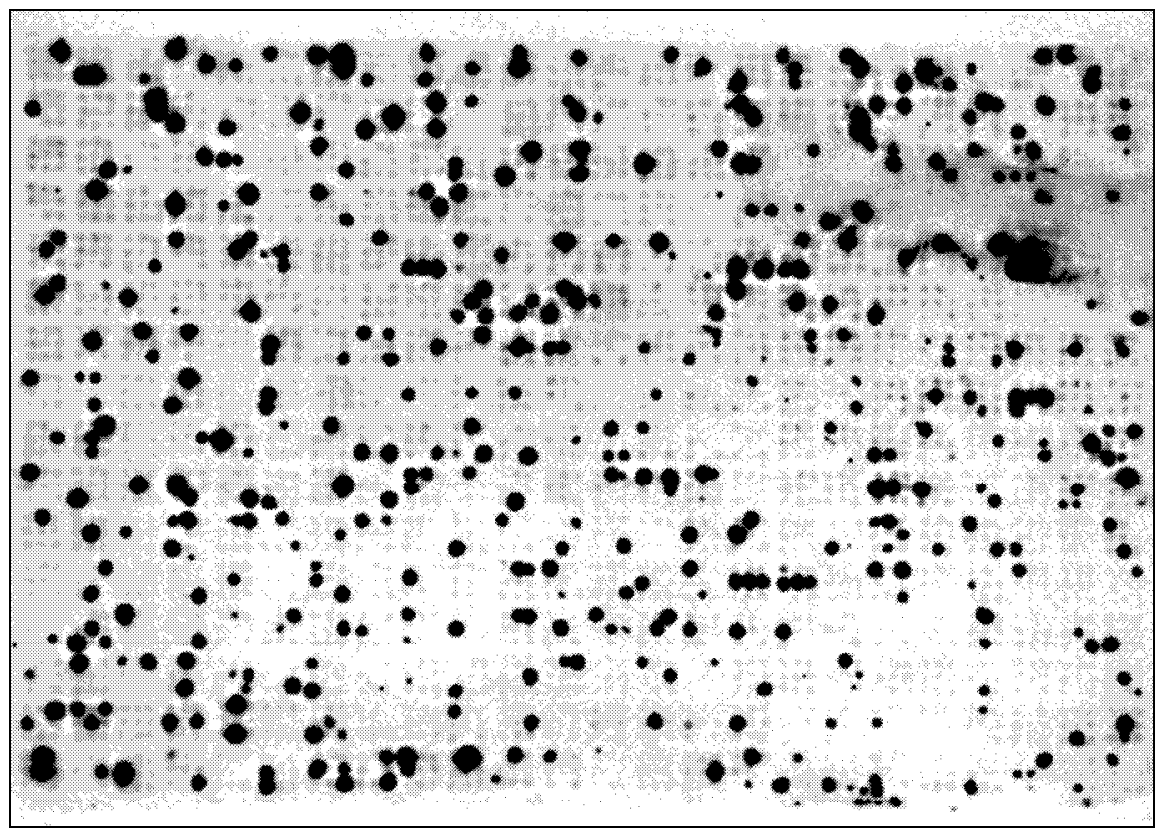

Figure 2. Colony Hybridization with Probes Tailed with dITP and DIG-dUTP. A total of 3456 colonies on an HDF were hybridized with probes tailed with dITP and DIG-dUTP. 
and the sensitivity of probes tailed with dITP and DIG-dUTP, in comparison with those of typical probes tailed with dATP and DIG-dUTP. The tail length was increased by the elevation of the dITP/DIG-dUTP ratio in the reaction mixture. The probe labeled with dITP and DIG-dUTP was slightly longer than that labeled with dATP and DIGdUTP, indicating efficient incorporation of dITP in the tail of the probe (data not shown). The signal intensity increased $10 \times$ by increasing the ratio of dITP:DIG-dUTP from 2/1 to 10/1 (data not shown). These results indicated that the highly sensitive tailed probe was prepared using a mixture of dITP and DIG-dUTP as substrates of TdT.

\section{Hybridization of cDNA clones with a Probe Tailed with dITP and DIG-dUTP}

To examine the hybridization characteristics of the tailed probes, nine types of cDNA clones containing poly(dA) regions from 23-140 bases long, but not containing sequences complementary to the designed sequence, were used as negative controls. The melting temperature of the original nucleotide of the probe was estimated to be $65^{\circ} \mathrm{C}$ in the hybridization solution according to a previously described method (9). Hybridization was carried out at $60^{\circ} \mathrm{C}, 5^{\circ} \mathrm{C}$ below the melting temperature. Regardless of the ratio of dITP/DIG-dUTP in the reaction mixture, specific hybridization of the probe tailed with dITP and DIG-dUTP was observed without the addition of poly (A) and poly (dA) mixed nucleotides (Figure 1, a and c).

In contrast, the probe tailed with dATP and DIG-dUTP did not specifically hybridize to TEGT cDNA without the addition of poly(A) and poly(dA) mixed nucleotides (Figure 1, a and c). Background hybridization was reduced by either decreasing the ratio of dATP/DIGdUTP in the reaction mixture or by adding poly (A) and poly (dA) mixed nucleotides (Figure 1a), however, background hybridization was not eliminated completely. These results suggest that the dI tails do not hybridize to any sequence of the cDNA clones, while the homopolymeric dA tails specifically hybridize to poly $(\mathrm{dT})$ regions of the cDNA clones under stringent conditions. It is possible that the poly(dI) tail have a lower melting temperature compared with the poly(dA) tail since $\mathrm{dI}: \mathrm{dG}$, dI:dT, dI:dA and dI:dT pairs are less stable than dA:dT pairs (6). The character of the tail is thought to result in the high specificity of hybridization.

\section{Colony Hybridization with Probes Tailed with dITP and DIG-dUTP}

Probes tailed with dITP and DIGdUTP were applied to colony hybridization screening. Oligonucleotides were designed for highly redundant genes in a library; 169 genes were selected, consisting of approximately $30 \%$ of the clones in the library. Oligonucleotides for 106 types of ribosomal protein $\mathrm{cD}$ NAs were also designed. Figure 2 shows the results of colony hybridization with the tailed oligonucleotides. Spots were labeled in an all-or-none manner, indicating high specificity. The probes did not hybridize to the genomic sequence of Escherichia coli. To confirm the results of the hybridization, 80 clones were selected in order and a single-pass sequence from the $5^{\prime}$-end was determined for each (Table 1). Among 58 clones with negative signals, three clones lacked the region to which the oligonucleotides were designed, indicating that the tailed probes did not hybridize with these cDNA clones. Among nine clones with positive signals, there was only one false positive. The clone may contain a sequence similar to the probe within the unsequenced region. Thus, it is shown that sensitive and specific hybridization can be carried out using the tailed probe in colony hybridization screening.

The oligonucleotide labeling described in this report did not require any specialized methods exception the use of dITP. We used the labeled 


\section{Short Technical Reports}

nucleotide DIG-dUTP as a model in the present study. It may be possible to use other labeled nucleotides, such as fluorescein-labeled nucleotides or biotinlabeled nucleotides. Oligonucleotide probes tailed with dITP and labeled nucleotide may facilitate cDNA screening by hybridization.

\section{REFER..ENCES}

1.Altschul, S.F. and W. Gish. 1996. Local alignment statistics, p. 460-480. In Methods in Enzymology, Vol. 266. Academic Press, NY.

2.Colgan, D.F. and J.L. Manley. 1997. Mechanism and regulation of mRNA polyadenylation. Genes Dev. 11:2755-2766.

3.Haralambidis, J., M. Chai and G.W. Tregear. 1987. Preparation of base-modified nucleosides suitable for non-radioactive label attachment and their incorporation into synthetic oligodeoxyribonucleotides. Nucleic Acids Res. 15:4857-4876.

4.Kempe, T., W.I. Sundquist, F. Chow and S.L. Hu. 1985. Chemical and enzymatic biotin-labeling of oligodeoxyribonucleotides.
Nucleic Acids Res. 13:45-57.

5.Kumar, A., P. Tchen, F. Roullet and J. Cohen. 1988. Nonradioactive labeling of synthetic oligonucleotide probes with terminal deoxynucleotidyl transferase. Anal. Biochem. 169:376-382.

6.Martin, F.H., M.M. Castro, F. Aboul-ela and I. Tinoco, Jr. 1985. Base pairing involving deoxyinosine: implications for probe design. Nucleic Acids Res. 13:8927-8938.

7.Maxam, A.M. and W. Gilbert. 1980. Sequencing end-labeled DNA with base-specific chemical cleavages. In Methods in Enzymology, Vol. 65, p. 499-560, Academic Press, NY.

8.Nizetic, D., R. Drmanac and H. Lehrach. 1991. An improved bacterial colony lysis procedure enables direct DNA hybridisation using short $(10,11$ bases) oligonucleotides to cosmids. Nucleic Acids Res. 19:182.

9.Sambrook, J., E.F. Fritsch and T. Maniatis. 1989. Molecular Cloning: A Laboratory Manual, Second edition, CSH Laboratory Press, Cold Spring Harbor, NY.

10.Sommerfelt, H., A.M. Svennerholm, K.H. Kalland, B.I. Haukanes and B. Bjorvatn. 1988. Comparative study of colony hybridization with synthetic oligonucleotide probes and enzyme-linked immunosorbent assay for identification of enterotoxigenic Escherichia coli. J. Clin. Microbiol. 26:530-534.

11.Suzuki, Y., K. Yoshitomo-Nakagawa, K. Maruyama, A. Suyama and S. Sugano. 1997. Construction and characterization of a full length-enriched and a 5 '-end-enriched cDNA library. Gene 200:149-156.

12.van Belkum, A., E. Linkels, T. Jelsma, F.M. van den Berg and W. Quint. 1994. Non-isotopic labeling of DNA by newly developed hapten-containing platinum compounds. BioTechniques 16:148-153.

We thank Dr. S. Sugano for the cDNA library. Address correspondenct to Dr. Tomoyasu Sugiyama, Helix Research Institute, Inc., 1532-3 Yana, Kisarazu-shi, Chiba 2920812 Japan.Internet: sugiyama@hri.co.jp

Received 20 August 1999; accepted 1 November 1999.

T. Sugiyama, S. Ishii, K. Saito, J. Yamamoto, T. Isogai and

T. Ota

Helix Research Institute

Chiba, Japan 